\title{
A EDUCAÇÃO EM TEMPO INTEGRAL NAS PUBLICAÇÕES PERIÓDICAS: APONTAMENTOS INICIAIS ${ }^{1}$
}

\section{FULL-TIME EDUCATION IN PERIODICALS: INITIAL NOTES \\ EDUCACIÓN DE TIEMPO COMPLETO EN LAS PUBLICACIONES PERIÓDICAS: APUNTES INICIALES}

Mariana Lubarino Vilas Boas ${ }^{2}$ mariana.l@aluno.ifsp.edu.br

Andréia Silva Abbiati ${ }^{3}$ andreia.abbiati@ifsp.edu.br

\section{RESUMO}

Com a promulgação da Lei de Diretrizes e Bases da Educação Nacional, Lei $\mathrm{n}^{\circ}$. 9.394/1996, as propostas de ampliação da jornada escolar vêm ganhando mais espaço no âmbito das políticas educacionais brasileiras. Inspirados nas experiências de Anísio Teixeira (1950), na Bahia, e de Darcy Ribeiro (1983), no Rio de Janeiro, diferentes estados e municípios elaboram suas propostas de educação em tempo integral apresentando, para tanto, diferentes justificativas. Diante do exposto, apresenta-se como objetivo deste trabalho, evidenciar e analisar os dados do levantamento bibliográfico realizado na base de dados da biblioteca online SciELO, ao longo de pesquisa de iniciação científica, relacionada à temática da educação em tempo integral. Os dados pesquisados revelaram que os estudos sobre a educação em tempo integral iniciaram-se nos anos 2000 com um aumento nas publicações periódicas a partir de 2012, sendo que um total de noventa autores se dedicou a esses estudos. O prosseguimento da pesquisa poderá revelar se o direito das crianças e jovens por uma educação integral vem sendo ou não, progressivamente, conquistado.

PALAVRAS-CHAVE: EDUCAÇÃO INTEGRAL; EDUCAÇÃO EM TEMPO INTEGRAL; AMPLIAÇÃO DA JORNADA ESCOLAR; POLÍTICAS EDUCACIONAIS.

\section{ABSTRACT}

With the promulgation of the Law of Guidelines and Bases of National Education, Law $\mathrm{n}^{\circ}$. 9.394/1996, the proposals of expansion of the school day have been gaining more and more space in the scope of Brazilian educational policies. Inspired by the

\footnotetext{
1 Este artigo faz parte de pesquisa de iniciação científica em andamento fomentada pelo Instituto Federal de São Paulo (IFSP), cujo projeto de pesquisa tem como tema "A implementação da meta 6 do Plano Nacional de Educação (2014-2024) no município de São João da Boa Vista/SP”.

2 Instituto Federal de Educação, Ciência e Tecnologia de São Paulo (IFSP), Campus São João da Boa Vista. 3 Instituto Federal de Educação, Ciência e Tecnologia de São Paulo (IFSP), Campus São João da Boa Vista.
} 
experiences of Anísio Teixeira (1950), in Bahia, and Darcy Ribeiro (1983), in Rio de Janeiro, different states and municipalities develop their proposals for full-time education with different justifications. Given the above, the objective of this work is to highlight and analyze the data from the bibliographic research conducted in the online SciELO library database, throughout scientific initiation research, related to the theme of full-time education. The researched data revealed that studies on full-time education began in the 2000s with an increase in periodical publications from 2012, and a total of ninety authors dedicated themselves to these studies. The continuation of the research may reveal whether or not the right of children and young people to an integral education has been progressively achieved.

KEYWORDS: INTEGRAL EDUCATION; FULL-TIME EDUCACION; EXPANSION OF THE SCHOOL DAY; EDUCATIONAL POLICIES.

\section{RESUMEN}

Con la promulgación de la Ley de Directrices y Bases de la Educación Nacional, Ley n 9.394/1996, las propuestas de ampliación de la jornada escolar han ganado más espacio en el ámbito de las políticas educacionales brasileñas. Inspirados en las experiencias de Anísio Teixeira (1950), en Bahia y de Darcy Ribeiro (1983), en Rio de Janeiro, muchos estados y municipios desarrollaron sus propuestas de educación de tiempo completo presentando, para ese propósito, justificativas distintas. Delante del expuesto, se presenta como objetivo de este trabajo, evidenciar y analizar los datos de la búsqueda bibliográfica hecha en la base de datos de la biblioteca en línea SciELO, a lo largo de la investigación de iniciación científica, en relación al tema de educación de tiempo completo. Los datos investigados enseñaron que los estudios sobre educación de tiempo completo empezaron en los años 2000 con un aumento en las publicaciones periódicas a partir de 2012, siendo que, un total de noventa autores han se dedicado a dichos estudios. El proseguimiento de la investigación podrá enseñar si el derecho de los niños y jóvenes de educación integral ha sido conquistado o no.

PALABRAS CLAVE: EDUCACIÓN INTEGRAL; EDUCACIÓN DE TIEMPO COMPLETO; AMPLIACIÓN DE LA JORNADA ESCOLAR; POLÍTICAS EDUCACIONALES.

\section{INTRODUÇÃO}

A aprovação da Lei de Diretrizes e Bases da Educação Nacional, Lei $n^{\circ}$. 9.394 de 20 de dezembro de 1996 (LDBEN/1996), pode ser considerada um dos instrumentos impulsionadores da ampliação das experiências de educação em tempo integral no Brasil. Em seu Artigo 34, determina que "a jornada escolar no ensino 
fundamental incluirá pelo menos quatro horas de trabalho efetivo em sala de aula, sendo progressivamente ampliado o período de permanência na escola", seguido, em seu parágrafo segundo, "o ensino fundamental será ministrado progressivamente em tempo integral, a critério dos sistemas de ensino" (BRASIL, 1996).

Da mesma forma, a Portaria Normativa Interministerial $n^{\circ}$. 17, de 24 de abril de 2007 instituiu o Programa Mais Educação (PME), visando "fomentar a educação integral de crianças, adolescentes e jovens, por meio do apoio a atividades sócioeducativas no contraturno escolar" (BRASIL, 2007). Em relação aos objetivos do programa, o artigo $1^{\circ}$ da Portaria do Ministério da Educação (MEC) prevê:

Art. $1^{\circ}$ Instituir o Programa Mais Educação, com o objetivo de contribuir para a formação integral de crianças, adolescentes e jovens, por meio da articulação de ações, de projetos e de programas do Governo Federal e suas contribuições às propostas, visões e práticas curriculares das redes públicas de ensino e das escolas, alterando o ambiente escolar e ampliando a oferta de saberes, métodos, processos e conteúdos educativos.

Parágrafo único. O programa será implementado por meio do apoio à realização, em escolas e outros espaços sócio-culturais, de ações sócioeducativas no contraturno escolar, incluindo os campos da educação, artes, cultura, esporte, lazer, mobilizando-os para a melhoria do desempenho educacional, ao cultivo de relações entre professores, alunos e suas comunidades, à garantia da proteção social da assistência social e à formação para a cidadania, incluindo perspectivas temáticas dos direitos humanos, consciência ambiental, novas tecnologias, comunicação social, saúde e consciência corporal, segurança alimentar e nutricional, convivência e democracia, compartilhamento comunitário e dinâmicas de redes (BRASIL, 2007).

Posteriormente, o Decreto $n^{\circ}$. 7.083, de 27 de janeiro de 2010, que dispõe sobre o PME, em seu Artigo $1^{\circ}$, declara:

Art. $1^{\circ} \mathrm{O}$ Programa Mais Educação tem por finalidade contribuir para a melhoria da aprendizagem por meio da ampliação do tempo de permanência de crianças, adolescentes e jovens matriculados em escola pública, mediante oferta de educação básica em tempo integral.

$\$ 1^{\circ}$ - Para os fins deste Decreto, considera-se educação básica em tempo integral a jornada escolar com duração igual ou superior a sete horas diárias, durante todo o período letivo, compreendendo o tempo total em que o aluno permanece na escola ou em atividades escolares em outros espaços educacionais (BRASIL, 2010).

Com foco em ser uma política educacional com previsão para realização de variadas atividades socioeducativas no contraturno escolar, o PME considera que a ampliação do tempo e dos espaços educativos pode ser a solução para os problemas de qualidade do ensino, assim como instrumento para o combate à pobreza, à exclusão social e à marginalização cultural (ROSA, 2012).

Além da LDBEN/1996 e do PME, o Plano Nacional de Educação (PNE) para o decênio 2014-2024, aprovado por meio da Lei nº 13.005/2014, determinou, em 
sua meta 6, "oferecer educação em tempo integral em, no mínimo, 50\% (cinquenta por cento) das escolas públicas, de forma a atender, pelo menos, $25 \%$ (vinte e cinco por cento) dos (as) alunos (as) da educação básica" (BRASIL, 2014). Observa-se, portanto, que as políticas educacionais brasileiras apontam para a ampliação do período de permanência do aluno na escola.

Há uma diferença substancial entre educação integral e educação em tempo integral. A educação integral trabalha com a multidimensionalidade do sujeito, procurando abarcar além da dimensão cognitiva, os sentimentos, as necessidades físicas, fisiológicas e outros fatores fundamentais da formação do indivíduo (GONÇALVES, 2006). Nas palavras deste autor:

O conceito mais tradicional encontrado para a definição de educação integral é aquele que considera o sujeito em sua condição multidimensional, não apenas na sua dimensão cognitiva, como também na compreensão de um sujeito que é sujeito corpóreo, tem afetos e está inserido num contexto de relações. Isso vale dizer a compreensão de um sujeito que deve ser considerado em sua dimensão bio-psicossocial (GONÇALVES, 2006, p. 130) (grifo do autor).

Gonçalves (2006) considera que a escola precisa ser repensada, de forma que compreenda os sujeitos como inteiros, ou seja, valorizando as vivências e experiências que as crianças e jovens passam ao longo da vida. Nesse sentido, a educação integral parte do princípio de compreender o estudante em sua totalidade, em sua multidimensão, já a educação em tempo integral, na visão do autor, deve ser pensada no sentido de ampliar as oportunidades de aprendizagens para os alunos, porém tendo a concepção de educação integral como alicerce.

Só faz sentido pensar na ampliação da jornada escolar, ou seja, na implantação de escolas de tempo integral, se considerarmos uma concepção de educação integral com a perspectiva de que o horário expandido represente uma ampliação de oportunidades e situações que promovam aprendizagens significativas e emancipadoras (GONÇALVES, 2006, p. 131) (grifo do autor).

A partir disso, tem-se a educação integral em tempo integral, onde a compreensão do sujeito multidimensional está presente simultaneamente à ampliação da jornada escolar, ambos contribuindo para aprendizagens significativas e emancipadoras dos sujeitos. Portanto, podem existir uma educação integral em jornada parcial e em jornada ampliada, ou apenas uma educação com o tempo ampliado, que não trabalha a multidimensionalidade do indivíduo.

Ao se aprofundar na história da educação brasileira, a concepção de educação integral se manifesta, no Brasil, no período da segunda república, com 
o Manifesto dos Pioneiros da Educação Nova, em $1932^{4}$. Entre um dos escritores desse documento, estava Anísio Spínola Teixeira que formulou projetos de educação integral e educação em tempo integral para o Rio de Janeiro e posteriormente para a Bahia (BRANCO, 2012).

As primeiras experiências de educação em tempo integral datam dos anos de 1950, quando Anísio Teixeira inaugurou, em Salvador (BA), o Centro Educacional Carneiro Ribeiro ${ }^{5}$, seguido pelos Centros Integrados de Educação Pública ${ }^{6}$ (CIEPs) criados por Darcy Ribeiro, no Rio de Janeiro (RJ), na década de 1980.

Essas duas experiências são importantes para se compreender os objetivos e princípios da educação integral. Anísio Teixeira assim descreve a função primordial do Centro Educacional Carneiro Ribeiro:

\begin{abstract}
A escola primária seria dividida em dois setores, o da instrução propriamente dita, ou seja, da antiga escola de letras; e o da educação propriamente dita, ou seja, da escola ativa. No setor da instrução, manter-se-ia o trabalho convencional da classe, o ensino da leitura, escrita, aritmética e mais ciências físicas e sociais; e no setor da educação as atividades socializantes, a educação artística, o trabalho manual, as artes industriais e a educação física (TEIXEIRA, 1962, p. 82).
\end{abstract}

Observa-se que a intenção da educação integral, conforme proposta por Anísio Teixeira, é que a educação fosse complementada por um programa pedagógico que contemplasse diferentes atividades socializantes no contraturno escolar, ou seja, uma educação integral de tempo integral.

De acordo com Cavaliere (2014), nesta perspectiva, a escola assume novas responsabilidades:

Além da instrução escolar, ela estaria implicada na educação física e moral, na educação para a cidadania, na educação para a sociedade da informação e da comunicação, na difusão cultural, na socialização primária no caso das crianças pequenas e, no caso dos jovens, na formação para o trabalho. Tudo isso seria parte da justificativa para a ampliação da jornada e conformaria o que vem sendo chamado de "educação integral" (CAVALIERE, 2014, p. 1207).

Essas novas responsabilidades assumidas pela escola implicam na necessidade de uma melhoria da infraestrutura e na contratação de funcionários e professores para ministrar as atividades no contraturno escolar (BRANCO, 2012).

\footnotetext{
4 "Refere-se a um documento escrito por 26 educadores, em 1932, com o título A reconstrução educacional no Brasil: ao povo e ao governo. Circulou em âmbito nacional com a finalidade de oferecer diretrizes para uma política de educação" (MENEZES, 2001).

5 Conhecido também como a Escola Parque de Salvador, é uma instituição de ensino pioneira no país por trazer a proposta então inovadora de educação integral voltada para as populações mais carentes.

6 Prédios escolares arquitetados por Oscar Niemeyer a fim de oferecer a educação em tempo integral durante o governo de Leonel Brizola no estado do Rio de Janeiro (1984-1988 e 1992-1996).
} 
Surgem desafios para a implementação da educação de tempo integral, principalmente envolvendo escassez de verbas e profissionais capacitados, o que por sua vez faz com que esta concepção de educação seja oferecida, prioritariamente, para a população mais carente, selecionando os bairros de maior vulnerabilidade para a sua instalação.

Cavaliere e Coelho (2003) analisam os CIEPs após 15 anos de sua implementação, e destacam a perpetuação da ideia de educação integral como ponto positivo. Porém, para as autoras, as escolas parecem não realizar um trabalho que poderia ser qualificado como educação integral, ocorrendo na realidade apenas a ampliação do tempo de permanência dos alunos nas escolas.

Diante do exposto, o presente trabalho tem como objetivo evidenciar e analisar os dados do levantamento bibliográfico realizado na base de dados da Scientific Electronic Library Online (SciELO), ao longo de uma pesquisa de iniciação científica relacionada à temática "educação em tempo integral".

\section{A EDUCAÇÃO EM TEMPO INTEGRAL NOS ARTIGOS CIENTÍFICOS}

Para a realização do levantamento bibliográfico seguiu-se o modelo de pesquisa proposto por Marconi e Lakatos (2010) no livro "Fundamentos de metodologia científica". Neste, as autoras apresentam etapas que devem ser realizadas em uma pesquisa bibliográfica científica, quais sejam: identificação, localização, compilação e fichamento, sendo que as três primeiras etapas foram utilizadas como estratégia de pesquisa neste trabalho.

De acordo com Marconi e Lakatos (2010), a fase de reconhecimento do assunto pertinente à temática estudada é conhecida como etapa de identificação. Nesta etapa, ocorreu a busca de obras relacionadas ao tema "educação integral" na base da SciELO.

A SciELO é uma biblioteca eletrônica que abrange uma coleção selecionada de periódicos científicos (SciELO, 2018), sendo, por este motivo, frequentemente utilizada em pesquisas científicas. Sua base de dados contempla uma extensa gama de artigos científicos dentro da área da educação.

Um motor de busca, também conhecido como "buscador", é um sistema de software projetado para procurar informações em uma base de dados e retorná-los de maneira organizada ao usuário, aproveitando-se da forma como a World Wide Web (Rede Mundial de Computadores, popularmente conhecida por Web) é organizada (GOOGLE, 2019).

Os sítios da internet são documentos de texto que ficam armazenados em computadores ligados em rede, disponíveis para acesso público. O que um motor de busca, (ou search engine) faz é cadastrar todos esses documentos em uma grande 
lista, ou índice, criando um banco de dados como uma espécie de catálogo. Os documentos web, por sua vez, contêm cabeçalhos com informações relevantes para estes motores de busca, tornando possível classificá-los para melhorar a efetividade das buscas no catálogo. Este procedimento é conhecido como indexação (GOOGLE, 2019).

Atualmente, este trabalho de procurar cada site e indexá-lo é feito por pequenos programas chamados de bots, ou robôs. Estes robôs atualizam o índice de sites automaticamente, alimentando o banco de dados e classificando as informações ali armazenadas de acordo com o nome do site, assunto de cada página, palavraschave, termos recorrentes no documento e outras informações específicas para cada buscador. Quando um usuário digita um termo para ser pesquisado, o que o motor de busca faz é comparar o termo com este catálogo previamente organizado em seu banco de dados, retornando os resultados que combinam com o termo de busca de maneira ordenada por probabilidade decrescente de combinação. O maior serviço de busca do mundo, o Google, explica como a indexação é feita em sua base:

A Web é como uma biblioteca que não para de crescer, com bilhões de livros e sem um sistema central de catálogo. Usamos softwares conhecidos como rastreadores da Web para detectar as páginas disponíveis ao público. Os rastreadores analisam as páginas e seguem os links delas, da mesma forma que você faria se estivesse navegando pelo conteúdo na Web. Eles vão de link em link e levam dados sobre essas páginas para os servidores do Google. [...] Quando os rastreadores encontram uma página da Web, nossos sistemas processam o conteúdo da página da mesma forma que um navegador. Detectamos os sinais importantes, como as palavras-chave e a idade do conteúdo do site, e registramos tudo isso no índice da Pesquisa (GOOGLE, 2019).

A pesquisa dos artigos na base da SciELO foi realizada com a utilização de palavras-chave relacionadas ao tema do estudo. As palavras-chave nada mais são do que termos que auxiliam na busca de artigos em determinada base de dados. É importante a escolha adequada das palavras-chave para se obter o resultado esperado. Para esta pesquisa, foram utilizadas as seguintes palavras-chave: educação integral, educação de tempo integral, educação em tempo integral, escola integral, escola de tempo integral e escola em tempo integral.

No site de busca, as palavras-chaves foram inseridas entre aspas ("'), as quais têm como função garantir que as palavras digitadas sejam procuradas exatamente da forma que foram digitadas na ferramenta de busca.

É importante lembrar que computadores não entendem palavras de maneira semântica, como os humanos (GOOGLE, 2019). Palavras são tratadas pelo computador como uma sequência (ou cadeia) de caracteres, conhecida na computação como string. Essa string pode ser alfabética, numérica ou alfanumérica, e para o computador 
não faz diferença se ela tem sentido em algum idioma humano ou não. O que ele faz é simplesmente comparar esta cadeia de caracteres com as informações que ele já tem indexadas (GOOGLE, 2019).

Para um motor de busca, como o da SciELO, as aspas encerram uma string que deve ser encontrada. $O$ buscador percorre sua base de dados procurando pela string entre aspas e retorna apenas os resultados que combinarem exatamente com os caracteres usados.

A utilização de aspas é importante para tornar a pesquisa mais precisa, pois o comportamento padrão dos motores de busca é levar em consideração os termos de pesquisa de maneira individual, ou seja, percorrer a base de dados combinando cada palavra no campo de busca com as palavras já indexadas, independentemente de estarem unidas no mesmo termo ou não. Por exemplo, ao se pesquisar por "educação integral", o termo será procurado exatamente dessa forma. Por outro lado, sem a utilização de aspas aparecerão na pesquisa todos os textos que possuem a palavra "educação" ou a palavra "integral", sem necessariamente estarem em conjunto. Pesquisar sem aspas torna a pesquisa mais abrangente, retornando um número maior de resultados, porém com precisão prejudicada.

O buscador da SciELO implementa o suporte a vários tipos de filtro de pesquisa. Estes filtros são seletores de busca que auxiliam na obtenção de resultados de acordo com o objetivo da pesquisa, afunilando o universo da mesma. Ou seja, ao invés do buscador percorrer toda a base de dados sem nenhum tipo de seleção prévia, os filtros delimitam a pesquisa a um número bem menor de dados pré-selecionados. Pode-se adicionar filtros de idiomas, ano de publicação, coleções, áreas temáticas, tipo de literatura, entre outros.

Para refinar os resultados da busca e para que eles estivessem melhor adequados ao objetivo do trabalho, aplicou-se alguns filtros. O primeiro, relacionado ao idioma, escolhendo-se os textos na língua nacional, o português. O segundo filtro, correspondente às áreas temáticas, optando-se por "ciências humanas" sendo a grande área e escolhendo-se como categorias temáticas "educação e pesquisa educacional" e "educação e disciplinas científicas". Este é o filtro mais relevante para a pesquisa, pois irá delimitar o assunto, que deve ser voltado para a educação. Por fim, o filtro do tipo de literatura definido como artigo.

Após este levantamento bibliográfico, foi realizada a localização das obras, ou seja, a obtenção do local em que as obras se encontram publicadas (MARCONI; LAKATOS, 2010), sendo que todas encontram-se na biblioteca SciELO e em seus periódicos científicos.

A norma NBR 6023/2002, da ABNT - Associação Brasileira de Normas Técnicas, define uma publicação periódica como "Publicação em qualquer tipo de 
suporte, editada em unidades físicas sucessivas, com designações numéricas e/ ou cronológicas e destinada a ser continuada indefinidamente" (ABNT, 2002, p.2). Os periódicos científicos publicam artigos, resultados de pesquisas científicas, entre outros. Pode-se dizer que os periódicos são como revistas, mas de caráter científico e encontram-se geralmente publicados em plataformas online.

Localizados os artigos, foi realizada a compilação dos mesmos, ou seja, a reunião sistemática do material, a qual pode ser realizada por meio de fotocópias, microfilmes, entre outros (MARCONI; LAKATOS, 2010). Escolheu-se fazer o download dos artigos para o andamento das etapas posteriores.

\section{APONTAMENTOS INICIAIS DO LEVANTAMENTO}

A coleta de dados foi realizada em 9 de setembro de 2019, utilizando as palavras-chave: "educação integral", "educação de tempo integral", "educação em tempo integral", "escola integral", "escola de tempo integral" e "escola em tempo integral" acrescidas dos filtros selecionados, etapa que gerou o total de 81 (oitenta e uma) ocorrências de artigos. Após a análise dos títulos dos artigos encontrados, notou-se que haviam artigos repetidos, que apareceram em mais de uma das palavras pesquisadas. Esses foram eliminados manualmente da contagem, restando 58 (cinquenta e oito) ocorrências únicas, ou seja, 58 (cinquenta e oito) artigos não repetidos.

A tabela 1 apresenta os números de ocorrências de artigos para cada uma das palavras-chave utilizadas durante a pesquisa na base de dados da biblioteca ScIELO.

TABELA 1. Ocorrências de artigos por palavras-chave.

\begin{tabular}{ccc}
\hline Palavras-chave & Ocorrências & Ocorrências únicas \\
\hline Educação Integral & 47 & 47 \\
Educação de Tempo Integral & 2 & 1 \\
Educação em Tempo Integral & 11 & 4 \\
Escola Integral & 2 & 0 \\
Escola de Tempo Integral & 13 & 5 \\
Escola em Tempo Integral & 6 & 1 \\
\hline Total de artigos & 81 & 58 \\
\hline
\end{tabular}

Fonte: Autoral, 2019. 
De acordo com os dados da Tabela 1, a palavra-chave que gerou uma maior incidência de artigos foi a "educação integral", com 47 (quarenta e sete) ocorrências. As outras palavras-chave utilizadas na busca apresentaram artigos que já apareciam na palavra-chave "educação integral", portanto o número de artigos das mesmas reduziu e o número da palavra-chave "educação integral" permaneceu o mesmo. Por exemplo, a palavra-chave "escola integral" ficou sem nenhuma ocorrência única, pois os artigos que a contemplavam, já se encontravam na palavra-chave "educação integral".

Ao se analisar os artigos encontrados, realizou-se a leitura dos resumos e das palavras-chave, além das informações primárias dos artigos, tais como periódico, autor(s) e ano de publicação. Após essa leitura prévia, obteve-se os números de autores, periódicos, anos de publicação, assim como os termos mais destacados nas palavras-chave relacionados a educação em tempo integral.

Constatou-se que os artigos estavam distribuídos em 12 (doze) periódicos diferentes. Dois deles possuíam apenas um artigo relacionado à educação integral, sendo o Pro-Posições e o Caderno Cedes. Os periódicos que publicaram o maior número de artigos abordando a temática foram: Educação \& Realidade, com 12 (doze) artigos; Ensaio: Avaliação e Políticas Públicas em Educação, com 10 (dez) artigos; Educar em Revista, com 9 (nove); e Educação em Revista, também com 9 (nove) artigos.

Em relação ao ano de publicação, o artigo mais antigo encontrado foi publicado em 2002, e os anos em que houve maior número de artigos publicados foram 2012, 2015, 2017 e 2018, com 8 (oito) artigos em cada ano.

O levantamento dos autores apontou um número total de 90 (noventa) autores. As autoras com o maior número de artigos publicados relacionados com a temática foram as professoras e doutoras em educação Lígia Martha C. C. Coelho e Maria Celeste Reis Fernandes Souza, com cinco artigos cada, seguidas pelas também professoras e doutoras em educação, Ana Maria Cavaliere e Lúcia Helena Alvarez Leite, com três artigos cada.

Analisou-se também as palavras-chaves dos artigos, observando que a palavra-chave "educação integral" estava presente em 34 (trinta e quatro) dos artigos, sendo a palavra-chave mais utilizada pelos autores. Palavras-chave relacionadas às políticas apareceram em 13 (treze) artigos (políticas públicas, políticas educacionais, política educacional, avaliação de políticas educacionais, entre outras). As palavraschave pertinentes à temática que também foram mencionadas são "escola de tempo integral", em seis artigos; "Programa Mais Educação", em seis publicações; e "educação em tempo integral", em cinco textos. 
Observou-se também que três artigos tratavam de experiências de Educação Integral em países da Europa. Outros dois não eram artigos, e sim uma resenha e um resumo de tese de doutorado. Um artigo chamou a atenção por trazer um mapeamento de publicações da área da educação sobre experiências de Educação Integral em âmbito nacional, do período 2007- 2012 e informações sobre as publicações.

Nota-se que a maioria dos artigos apresenta relação com a temática abordada, portanto a escolha dos filtros adequados e a utilização das aspas foi fundamental para a obtenção do resultado. $O$ número de artigos obtidos foi significativo, sendo 58 (cinquenta e oito) artigos, possibilitando um estudo amplo sobre o tema. Esses apontamentos iniciais proporcionaram uma visão geral sobre as publicações periódicas acerca da educação (em tempo) integral e a partir disso, pode-se dar andamento ao projeto de iniciação científica.

\section{CONSIDERAÇÕES FINAIS}

Baseando-se nos dados coletados, considera-se que a educação em tempo integral e a educação integral vêm sendo estudadas a partir dos anos 2000, com um aumento de publicações em 2012, portanto os estudos se iniciaram alguns anos após a aprovação da LDBEN/1996, legislação esta que impulsionou as redes de ensino a se organizarem para $o$ atendimento dos alunos em jornada ampliada.

A partir dos dados obtidos pode-se afirmar que a temática da educação em tempo integral tem sido objeto de estudo por parte de diferentes autores, a considerar o número de artigos publicados na base de dados pesquisada. Importante salientar, também, que a diversidade de periódicos encontrada revela o interesse da área cientifica pelo assunto.

Desse modo, as etapas posteriores a este levantamento, constantes da pesquisa de iniciação científica em desenvolvimento, preveem leitura e fichamento dos artigos selecionados, assim como a análise dos mesmos. Pretende-se encontrar nestes artigos, experiências de educação integral desenvolvidas no Brasil, a fim de observar como as políticas educacionais estão sendo desenvolvidas no país e identificar as suas potencialidades e/ou fragilidades.

O prosseguimento dos estudos pode levar a outras conclusões relacionadas se esse direito das crianças e jovens, conforme delineado na LDBEN/1996, bem como no PNE 2014-2024 vem sendo ou não, progressivamente, conquistado. 


\section{REFERÊNCIAS}

ASSOCIAÇÃO BRASILEIRA DE NORMAS TÉCNICAS. NBR 6023:2002: Informação e documentação - Referências - Elaboração. Rio de Janeiro, 2002. Disponível em: https://www.ufrgs.br/psicoeduc/arquivos/abnt-nbr-6023-referencias.pdf. Acesso em: 7 nov. 2019.

BRANCO, Veronica. Desafios para a implantação da Educação Integral: análise das experiências desenvolvidas na região sul do Brasil. Educar em Revista, Curitiba, n. 45, p. 111-123, jul./set., 2012. Disponível em: http://www.scielo.br/pdf/er/n45/08.pdf. Acesso em: 7 nov. 2019.

BRASIL. Decreto n. 7.083, de 27 de janeiro de 2010. Dispõe o Programa Mais Educação. Brasília, DF: MEC, 2010. Disponível em: http://www.planalto.gov.br/ ccivil_03/_Ato2007-2010/2010/Decreto/D7083.htm. Acesso em: 7 nov. 2019.

BRASIL. Lei n. 13.005, de 25 de junho de 2014. Aprova o Plano Nacional de Educação - PNE e dá outras providências. Brasília, DF: MF/MP/MEC, 2014. Disponível em: http://www.planalto.gov.br/ccivil_03/_ato2011-2014/2014/lei//13005.htm. Acesso em: 6 nov. 2019

BRASIL. Lei n. 9.394, de 20 de dezembro de 1996. Estabelece as diretrizes e bases da educação nacional. Brasília, DF: MEC, 1996. Disponível em: http://www.planalto. gov.br/ccivil_03/leis/L9394.htm. Acesso em: 6 nov. 2019.

BRASIL. Portaria normativa interministerial n. 17, de 24 de abril de 2007. Institui o Programa Mais Educação. Brasília, DF: MEC, 2007. Disponível em: http://portal.mec. gov.br/arquivos/pdf/mais_educacao.pdf. Acesso em: 6 nov. 2019.

CAVALIERE, Ana Maria. Escola pública de tempo integral no brasil: filantropia ou política de estado?. Educ. Soc., Campinas, v. 35, n. 129, p. 1205-1222, out./dez., 2014. Disponível em: http://www.scielo.br/pdf/es/v35n129/0101-7330-es-35-129-01205.pdf. Acesso em: 30 out. 2019.

CAVALIERE, Ana Maria; COELHO, Lígia Martha. Para onde caminham os Cieps? Uma análise após 15 anos. Cadernos de Pesquisa, n. 119, jul. 2003, p. 147-174, Disponível em: http://www.scielo.br/pdf/cp/n119/n119a08.pdf. Acesso em: 6 nov. 2019.

GONÇALVES, Antonio Sérgio. Reflexões sobre educação integral e escola de tempo integral. Cadernos Cenpec, v. 1, n. 6, 2006, p.129-135, Disponível em: http:// cadernos.cenpec.org.br/cadernos/index.php/cadernos/article/view/136. Acesso em: 12 nov. 2019. 
GOOGLE. Como funciona a Pesquisa Google. Google, 2019. Disponível em: https:// www.google.com/search/howsearchworks. Acesso em: 13 nov. 2019.

MARCONI, Marina de Andrade; LAKATOS, Eva Maria. Fundamentos de metodologia científica. 7. ed. São Paulo: Atlas, 2010.

MENEZES, Ebenezer Takuno de. Manifesto dos Pioneiros da Educação Nova. Dicionário Interativo da Educação Brasileira - Educabrasil. São Paulo: Midiamix, 2001. Disponível em: https://www.educabrasil.com.br/manifesto-dos-pioneiros-daeducacao-nova/. Acesso em: 13 nov. 2019.

ROSA, Viviane Silva da. O programa mais educação como política pública nacional de educação integral. In: IX ANPED SUL - Seminário de pesquisa em educação da região sul, 9., 2012, Caxias do Sul. Conferência [...]. Caxias do Sul: UCS, 2012. p. 1-15. Disponível em: http://www.ucs.br/etc/conferencias/index.php/anpedsul/9anpedsul/ paper/viewFile/1095/129. Acesso em: 30 out. 2019.

TEIXEIRA, Anísio Spínola. Uma experiência de Educação Primária Integral no Brasil. Revista Brasileira de Estudos Pedagógicos, Rio de Janeiro, v. 38, n. 87, p. 21-33, jul./set., 1962.

\section{SOBRE OS AUTORES}

MARIANA LUBARINO VILAS BOAS. Graduanda em Licenciatura em Ciências Naturais com habilitação em Química pelo Instituto Federal de Educação, Ciência e Tecnologia de São Paulo (IFSP), Campus São João da Boa Vista. Participante de projeto de iniciação científica fomentado pelo IFSP (2019-2020). Professora de educação básica no município de São João da Boa Vista. Instituição: Instituto Federal de Educação, Ciência e Tecnologia de São Paulo (IFSP).

ANDRÉIA SILVA ABBIATI. Docente da área de Educação/Pedagogia do Instituto Federal de Educação, Ciência e Tecnologia de São Paulo (IFSP), Campus São João da Boa Vista e pesquisadora do Laboratório de Gestão Educacional (LAGE/UNICAMP). Doutora em Educação pela Faculdade de Educação da UNICAMP (2019), Mestre em Educação pela UNIMEP (2008), Especialista em Gestão da Rede Pública pela USP de Ribeirão Preto (2011) e em Gestão Educacional pela UNICAMP (2006), Licenciada em Ciências com Habilitação em Matemática pelas Faculdades Integradas Maria Imaculada (1994) e em Pedagogia pelo Centro Universitário Amparense - UNIFIA (1998). Possui experiência na área educacional, com ênfase em políticas públicas e sistemas de ensino, desenvolvendo pesquisas relacionadas às temáticas direito 


\section{REVISTA @imbienteeducação}

VILAS BOAS, ML; ABBIATI, AS. A educação em tempo integral nas publicações periódicas: apontamentos iniciais. Revista @mbienteeducação. São Paulo: Universidade Cidade de São Paulo, v. 13, n. 2, p. 160-173 Mai/Ago 2020.

à educação, educação (em tempo) integral, planejamento educacional e formação de professores. Integra o Banco de Avaliadores do Sistema Nacional de Avaliação da Educação Superior (BASIs). Instituição: Instituto Federal de Educação, Ciência e Tecnologia de São Paulo (IFSP).

RECEBIDO: $17 / 04 / 2020$.

APROVADO: 22/04/2020. 